\title{
The expo-power value function as a candidate for the work-horse specification in parametric versions of cumulative prospect theory
}

\author{
D.A. Peel ${ }^{*}$, Jie Zhang \\ University of Lancaster, United Kingdom
}

\section{A R T I C L E I N F O}

\section{Article history:}

Received 1 March 2008

Received in revised form 1 September 2009

Accepted 5 September 2009

Available online 12 September 2009

\section{Keywords:}

Cumulative prospect theory

Expo-power value function

Exponential value function

JEL classification:

C72

C92

D80

D84

\section{Introduction}

The parametric version of cumulative prospect theory proposed by Tversky and Kahneman (1992) ( $\mathrm{T}$ and $\mathrm{K}$ ) to accommodate violations of standard expected utility assumes a piecewise power value function. This formulation has been employed in a great deal of experimental and theoretical analysis. For instance the power value parameters have been estimated from experimental data, see e.g. Tversky and Kahneman (1992), Camerer and Teck-Hua (1994), Wu and Gonzalez (1996) and Abdellaoui et al. (2007). From a theoretical perspective the formulation has been employed, for example, to explain the equity risk premium puzzle (Benartzi and Thaler, 1995) or that in contrast to standard expected utility that a security's own skewness can be priced (Barberis and Huang, 2008).

However there is also a literature, which suggests that many experimental outcomes and theoretical analyses are inconsistent with the assumption of power value functions. For instance Neilson and Stowe (2002) consider a number of experimental results and show that the $\mathrm{T}$ and $\mathrm{K}$ specification cannot simultaneously account for both the Allais paradox over large payoff choices and other strong choice patterns from experiments. They state that the most obvious

\footnotetext{
* Corresponding author. Lancaster University Management School, Lancaster, LA1 4YX, United Kingdom. Tel.: +44 152465201; fax: +44 1524594244.

E-mail address: d.peel@lancaster.ac.uk (D.A. Peel).
}

conclusion of their work is that alternative functional forms are needed.

This finding is supported by the experimental results reported by Binswanger (1980), Hershey and Shoemaker (1980) and Holt and Laury (2002). In their experiments the probabilities, in a sequence of gambles, are kept fixed as agents choose either between a gamble and its certainty equivalent or between a "safer" and "more risky" gamble. They found that increases in payoff levels, real or hypothetical, lead agents to switch their choice from the gamble (more risky gamble) to the certainty equivalent (safer gamble).This switch in choice, given probabilities remain fixed, is also in consistent with a power value function.

Rieger (2007) also notes that the power value function cannot describe the very risk-averse choices made in some experiments involving two-outcome lotteries.

There are also theoretical limitations of the power value function in applications in finance. For example De Giorgi and Hens (2006) consider some applications in portfolio theory. They demonstrate that the power value function leads to the non-existence of equilibrium and suggest the exponential function as an alternative.

Another limitation of the power value function is that it violates the assumption of loss aversion for small enough symmetric gains or losses (see e.g. Köbberling and Wakker (2005), Schmidt and Zank (2005)). In fact the agent ultimately becomes gain seeking, rather than loss-averse over small enough symmetric gambles. As a consequence any optimal model of gambling based on power value 
functions will imply violation of the loss aversion assumption in $\mathrm{T}$ and K (see e.g. Cain et al. (2008)).

An expo-power value function nests both the power and exponential value functions. Our purpose in this letter is to demonstrate that the assumption of an expo-power value function is consistent, depending on the degree of probability distortion assumed, to explain all or nearly all the majority choices in ten Allais experiments involving both small and large payoffs. Neither the power, or to a lesser extent, the exponential value functions can do this. In addition because the expo-power function also nests the exponential value function it can also be employed in nonexperimental areas such as portfolio selection.

\section{Some analysis}

Cumulative prospect theory as set out by $\mathrm{T}$ and $\mathrm{K}$, using the notation and formulation of Neilson and Stowe, has the following general form for a gamble composed of $m+n+1$ monetary outcomes, $x_{-m},<\ldots<x_{0}<\ldots<x_{n}$, which occur with probabilities $p_{-m}, \ldots$, $p_{n}$, respectively.

$V(x ; p)=V^{+}(x ; p)+V^{-}(x: p)$

$V^{+}(x ; p)=g\left(p_{n}\right) u\left(x_{n}\right)+\sum_{k=1}^{n}\left[g\left\{\sum_{j=0}^{k} p_{n-j}\right\}-g\left\{\sum_{j=0}^{k-1} p_{n-j}\right\}\right] u\left(x_{n-k}\right)$

$V^{-}(x ; p)=g\left(p_{-m}\right) u\left(x_{-m}\right)+\sum_{k=1}^{m}\left[g\left\{\sum_{j=0}^{k} p_{-(m-j)}\right\}-g\left\{\sum_{j=0}^{k-1} p_{-(m-j)}\right\}\right] u\left(x_{-(m-k)}\right)$

The preference value of the gamble is given by Eq. (1) where $V^{+}$ measures the value of gains, and $V^{-}$measures the value of losses. The value or utility function is given by $u(x)$ with $u(x)=0$. The function $g(p)$ is a probability weighting function assumed to be increasing with $g(0)=0$ and $g(1)=1$.

In their parametric formulation $\mathrm{T}$ and $\mathrm{K}$ assumed that the probability weighting function over gains is given by

$g(p)=\frac{p^{\delta}}{\left[p^{\delta}+(1-p)^{\delta}\right]^{\frac{1}{\delta}}}$

where $0<\delta<1$.

This function implies that small probabilities are over weighted and larger ones under weighted.

Assuming the power value function

$u(x)=x^{\alpha}$

where $0<\alpha<1$ an example of the $\mathrm{T}$ and $\mathrm{K}$ formulation of the expected value of the three outcome gamble, zero, $\$ 1, \$ 5$ with probabilities $0.01,0.89$ and 0.1 respectively is given by ${ }^{1}$

$$
\begin{aligned}
V^{+}= & \frac{0.1^{\delta}}{\left[0.1^{\delta}+(0.9)^{\delta}\right]^{\frac{1}{\delta}}} 5^{\alpha}+\left[\frac{0.99^{\delta}}{\left[0.99^{\delta}+(0.01)^{\delta}\right]^{\frac{1}{\delta}}}-\frac{0.1^{\delta}}{\left[0.1^{\delta}+(0.9)^{\delta}\right]^{\frac{1}{\delta}}}\right] 1^{\alpha} \\
& +\left[1-\left(\frac{0.99^{\delta}}{\left[0.99^{\delta}+(0.01)^{\delta}\right]^{\frac{1}{\delta}}}\right)\right] 0^{\alpha}
\end{aligned}
$$

\footnotetext{
${ }^{1}$ As noted by Neilson and Stowe (2002) in cumulative prospect theory, whether for gains or losses extreme outcomes are weighted first. They note this differs from rank dependent utility of Quiggin (1993).
}

The expo-power function of Saha (1993) defined over gains is given by

$u(x)=1-e^{-r x^{n}}$

where $r$ and $n$ are positive constants.

For $n \leq 1$ the agent is everywhere risk-averse over gains as postulated by $\mathrm{T}$ and K. For $n=1$ we obtain the exponential function.

The expo-power function also has the convenient property, found by employing L'Hopital's rule, that as $r \rightarrow 0$ the function approximates the power value function. ${ }^{2}$

In Table 1 we report the parameter values that are consistent with the majority choices in a number of Allais experiments when we employ the probability weighting function $(4)^{3}$ in conjunction with a power value function, an exponential value function and the expopower function.

The ten Allais experiments we employ are the choices between

(a) A: a certain 1 million or $\mathrm{B}$ : a $p=0.89$ chance of 1 million, $p=0.1$ chance of 5 million and $p=0.01$ chance of nothing (Allais, 1953)

(b) C: $p=0.10$ chance of 5 million or $\mathrm{D}$ : a $p=0.11$ chance of 1 million (Allais, 1953)

(c) E: a certain 3000 or F: a $p=0.80$ chance of 4000 (T and K (1992))

(d) G: a $p=0.20$ chance of 4000 or H: a $p=0.25$ chance of 3000 ( T and $\mathrm{K}(1992)$ )

(e) I: a certain 2400 or $\mathrm{J}$ : a $p=0.66$ chance of $2400, p=33$ chance of 2500 and $p=0.01$ chance of nothing ( $\mathrm{T}$ and $\mathrm{K}(1992)$ )

(f) K: a $p=0.33$ chance of 2500 or L: a $p=0.34$ chance of 2400 ( $\mathrm{T}$ and $\mathrm{K}(1992)$ )

(g) M: a certain 5 or $\mathrm{N}$ : a $p=0.89$ chance of $5, p=0.1$ chance of 25 and $p=0.01$ chance of nothing (Conlisk, 1989)

(h) $\mathrm{O}$ : a $p=0.10$ chance of 25 or $\mathrm{P}: \mathrm{a} p=0.11$ chance of 5 (Conlisk, 1989)

(i) Q: a certain 7 or $\mathrm{R}$ : a $p=0.75$ chance of $7, p=0.2$ chance of 10 million and, $p=0.05$ chance of nothing (List and Haigh, 2005)

(j) S: $p=0.2$ chance of 10 or $\mathrm{T}$ : a $p=0.25$ chance of 7 . (List and Haigh, 2005)

In each case the majority choice in their experiments is the first in the pair of choices, e.g. A>B,

$Q>R$.

$\mathrm{T}$ and $\mathrm{K}$ suggested parameter values of $n=0.88$ and $\delta=0.61$ for the power value parameter and the probability distortion parameter respectively.

We note immediately from Table 1 that the parametric formulation of $\mathrm{T}$ and $\mathrm{K}$ cannot simultaneously explain the majority choice in the original classic large stake Allais experiment, $\mathrm{A}>\mathrm{B}$, and other experiments involving larger stakes. For example the value of the power exponent required to explain the majority choices, $A>B$ and $\mathrm{G}>\mathrm{H}$ or $\mathrm{K}>\mathrm{L}$ given degrees of probability distortion captured by $0.61 \leq \delta \leq 0.9$ are inconsistent.

Of course the power function cannot be consistent with a majority choice of the safe outcome in large payoff Allais experiments and the risky choice in small payoff experiments given they involve the same probabilities and differ solely by a constant scale factor. This is the case for experiments with the choices $A>B$ and $M>N$.

\footnotetext{
${ }^{2}$ Easily seen by dividing the expo-power function by the arbitrary constant $1-e^{-r}$. We also experimented with the double expo-power value function $U(x)=\frac{1-e^{-\frac{r\left(1-e^{-\theta t x^{n}}\right)}{1-e^{-\theta}}}}{1-e^{-r}}$ where $r$ and $\theta$ are positive constants. This function is everywhere risk-averse over gains but has the properties that as $\theta \rightarrow 0$ the function approximates the expo-power value function and as $r \rightarrow 0$ and $\theta \rightarrow 0$ the power value function. In fact it made little difference for the range of payoffs we consider here.

${ }^{3}$ Employing the form in Prelec (1998) makes no major difference to our results.
} 
Table 1

Parameter values for majority choices in certain Allais experiments.

\begin{tabular}{|c|c|c|c|c|c|c|c|c|c|}
\hline \multirow[t]{3}{*}{ Majority choice e.g. $A>B, K>L$} & \multirow{2}{*}{\multicolumn{3}{|c|}{ Power }} & \multicolumn{3}{|l|}{ Expo-power } & \multicolumn{3}{|l|}{ Expo-power } \\
\hline & & & & \multicolumn{3}{|l|}{$n=1$} & \multicolumn{3}{|l|}{$r=0.00001$} \\
\hline & $\delta=0.61$ & $\delta=0.85$ & $\delta=0.90$ & $\delta=0.61$ & $\delta=0.85$ & $\delta=0.90$ & $\delta=0.61$ & $\delta=0.85$ & $\delta=0.90$ \\
\hline $\begin{array}{l}\text { Allais } A>B \\
\text { A. } \$ 1,000,000 \\
\text { B. } \$ 1,000,000 * 89 \%+\$ 5,000,000 * 10 \%\end{array}$ & $n<0.241$ & $n<0.094$ & $n<0.079$ & $r>0.0000012$ & $r>0.0000020$ & $r>0.0000022$ & $\begin{array}{l}n<0.241 \text { or } \\
n>0.841\end{array}$ & $\begin{array}{l}n<0.094 \text { or } \\
n>0.883\end{array}$ & $\begin{array}{l}n<0.079 \text { or } \\
n>0.888\end{array}$ \\
\hline $\begin{array}{l}\text { Allais C>D } \\
\text { C. } \$ 5,000,000 * 10 \% \\
\text { D. } \$ 1,000,000 * 11 \%\end{array}$ & $n>0.029$ & $n>0.049$ & $n>0.052$ & $r<0.000003$ & $r<0.00000259$ & $r<0.0000025$ & $0.029<n<0.914$ & $0.0481<n<0.902$ & $0.052<n<0.900$ \\
\hline $\begin{array}{l}\text { KT } E>F \\
\quad \text { E. } \$ 3000 \\
\text { F. } \$ 4000 * 80 \%\end{array}$ & $n<1.732$ & $n<0.981$ & $n<0.897$ & any & $r>0.000011$ & $r>0.000062$ & any & $\begin{array}{l}n<0.997 \text { or } \\
n>1.352\end{array}$ & $\begin{array}{l}n<0.904 \text { or } \\
n>1.388\end{array}$ \\
\hline $\begin{array}{l}\text { KT G>H } \\
\text { G. } \$ 4000 * 20 \% \\
\text { H. } \$ 3000 * 25 \%\end{array}$ & $n>0.379$ & $n>0.626$ & $n>0.676$ & $r<0.00049$ & $r<0.00025$ & $r<0.00021$ & $0.379<n<1.517$ & $0.626<n<1.463$ & $0.677<n<1.451$ \\
\hline $\begin{array}{l}\text { KT I }>\text { J } \\
\text { I. } \$ 2400 \\
\text { J. } \$ 2500 * 33 \%+\$ 2400 * 66 \%\end{array}$ & any & $n<1.481$ & $n<1.148$ & any & any & any & any & any & any \\
\hline $\begin{array}{l}\text { KT K }>\mathrm{L} \\
\text { K. } \$ 2500 * 33 \% \\
\text { L. } \$ 2400 * 34 \%\end{array}$ & $n>0.378$ & $n>0.596$ & $n>0.642$ & $r<0.00069$ & $r<0.00039$ & $r<0.00033$ & $0.378<n<1.587$ & $0.597<n<1.541$ & $0.642<n<1.531$ \\
\hline $\begin{array}{l}\text { Conlisk } M>N \\
\text { M. } \$ 25 * 10 \%+\$ 5 * 89 \% \\
\text { N. } \$ 5\end{array}$ & $n>0.242$ & $n>0.095$ & $n>0.080$ & $r<0.225$ & $r<0.392$ & $r<0.424$ & $n>0.242$ & $n>0.095$ & $n>0.080$ \\
\hline $\begin{array}{l}\text { Conlisk } \mathrm{O}>\mathrm{P} \\
\text { O. } \$ 25^{*} 10 \% \\
\text { P. } \$ 5^{*} 11 \%\end{array}$ & $n>0.029$ & $n>0.049$ & $n>0.052$ & $r<0.617$ & $r<0.519$ & $r<0.504$ & $n>0.029$ & $n>0.049$ & $n>0.052$ \\
\hline $\begin{array}{l}\text { List \& Haigh Q>R } \\
\text { Q. } \$ 10 * 20 \%+\$ 7 * 75 \% \\
\text { R. } \$ 7\end{array}$ & $n>1.638$ & $n>0.843$ & $n>0.753$ & None & $r<0.0396$ & $r<0.064$ & $n>1.638$ & $n>0.843$ & $n>0.753$ \\
\hline $\begin{array}{l}\text { List \& Haigh } S>\text { T } \\
\text { S. } \$ 10 * 20 \% \\
\text { T. } \$ 7 * 25 \%\end{array}$ & $n>0.306$ & $n>0.505$ & $n>0.546$ & $r<0.243$ & $r<0.148$ & $r<0.132$ & $n>0.306$ & $n>0.505$ & $n>0.546$ \\
\hline Overall & None & None & None & None & None & None & None & $0.883<n<0.902$ & $0.888<n<0.900$ \\
\hline
\end{tabular}

Employing a small value of $r$ the expo-power function approximates the power function over small payoff outcomes. We employ a value of $r=0.00001$. Not surprisingly we observe in Table 1 that the value of the exponent in the expo-power required to obtain the majority outcomes over small payoffs, for the given degrees of probability distortion, $\mathrm{M}>\mathrm{N}, \mathrm{O}>\mathrm{P}, \mathrm{Q}>\mathrm{R}$, and $\mathrm{S}>\mathrm{T}$, are identical for the power and expo-power functions. However unlike the power function the expo-power function now permits a range of parameter values that are consistent with majority choices over both large and small payoffs. For instance values of $n=0.88$ and $\delta=0.61$ are consistent with the majority outcomes in all the experiments except the small stake payoff of List and Haigh $(\mathrm{Q}>\mathrm{R})$. In order to explain this majority outcome we require less probability distortion than assumed by $\mathrm{T}$ and K. In fact with lower degrees of probability distortion assumed, $\delta$ around 0.85 , the expo-power function permits a range of values that are consistent with all majority choices. This falls into the surprisingly narrow range $0.882 \leq n \leq 0.902$.

The exponential function is nested by the expo-power function. We observe that with a small value of $r$, in the range $0.000002<$ $r<0.0000259$ (experiments $\mathrm{A}>\mathrm{B}, \mathrm{C}>\mathrm{D}$ ), the function is consistent with all the majority choices except List and Haigh $(Q>R)$. However for lower degrees of probability distortion this is not the case and the function is inconsistent with the majority choices $C>D$ and $E>F$.

\section{Conclusion}

There is a great deal of experimental as well as theoretical research that is inconsistent with the assumption of a power value specification in cumulative prospect theory.

The expo-power function, for suitable parameter values, nests the power value function and also the exponential function. We considered ten Allais experiments involving large and small payoffs and calculated the parameter values consistent with the majority choices.

We showed that the expo-power function can, unlike the power or exponential value function, explain the majority outcomes in all ten different Allais experiments, involving both small and large payoffs, when the degree of probability is less than assumed by T and K. However the feasible range of parameter values in this case is surprisingly narrow.

When the degree of probability distortion is the same as that assumed by $\mathrm{T}$ and $\mathrm{K}$ the expo-power function can explain all except one of the majority choices. This is the experiment over small stakes of List and Haigh (2005). This experiment is surely worthy of replication since a majority choice of the risky option implies a degree of probability distortion which is substantially less than assumed by $\mathrm{T}$ and $\mathrm{K}$.

\section{References}

Abdellaoui, B.M., Bleichrodt, H., Paraschiv, C., 2007. Loss aversion under prospect theory: a parameter free measurement. Management Science 53, 1659-1674.

Allais, M., 1953. Le Comportement de l'Homme Rationnel devant le Risque: Critique des Postulats et Axiomes de l'Ecole Américaine. Econometrica 21, 503-546.

Barberis, N., Huang, M., 2008. Stocks as lotteries: the implications of probability weighting for security prices. American Economic Review 98, 2066-2100.

Benartzi, S., Thaler, R.T., 1995. Myopic loss aversion and the equity premium puzzle. The Quarterly Journal of Economics 110 (1), 73-92.

Binswanger, H.P., 1980. Attitude toward risk: experimental measurement in rural India. Journal of Agricultural Economics 62, 395-407.

Cain, M., Law, D., Peel, D.A., 2008. Bounded cumulative prospect theory and gambling. Applied Economics 40 (1), 5-15.

Camerer, C.F., Teck-Hua, H., 1994. Violations of the betweenness axiom and nonlinearity in probability. Journal of Risk and Uncertainty 8, 167-196.

Conlisk, J., 1989. Three variants on the Allais example. The American Economic Review 79 (3), 392-407.

De Giorgi, E., Hens, T., 2006. Making prospect theory fit for finance. Financial Markets and Portfolio Management 20 (3), 339-360.

Hershey, J.C., Shoemaker, P.J.H., 1980. Prospect theory's reflection hypothesis: a critical examination. Organizational Behavior and Human Performance 25, 395-418. 
Holt, C.A., Laury, S.K., 2002. Risk aversion and incentive effects. American Economic Review 92 (5), 1644-1655.

Köbberling, V., Wakker, P., 2005. An index of loss aversion. Journal of Economic Theory $122,119-131$.

List, J.A., Haigh, M., 2005. A simple test of expected utility theory using professional traders. Proceedings of the National Academy of Science 102 (3), 945-948.

Neilson, W.S., Stowe, J., 2002. A further examination of cumulative prospect theory parameterizations. Journal of Risk and Uncertainty 24, 31-46.

Prelec, D., 1998. The probability weighting function. Econometrica 66, 497-527.

Quiggin, J., 1993. Generalized Expected Utility Theory: The Rank-dependent Model. Kluwer Academic Publishers, Dordrecht.
Rieger, M.O., 2007. Too risk averse for Prospect Theory? Mimeo University of Zurich. Saha, A., 1993. Expo-power utility: a flexible form for absolute and relative risk aversion. American Journal of Agricultural Economics 75, 905-913.

Schmidt, U., Zank, H., 2005. What is loss aversion? The Journal of Risk and Uncertainty 30, 157-167.

Tversky, A., Kahneman, D., 1992. Advances in prospect theory: cumulative representation of uncertainty. Journal of Risk and Uncertainty 5 (4), 297-323.

Wu, G., Gonzalez, R., 1996. Curvature of the probability weighting function. Management Science 42, 1676-1690. 